\title{
International standards on drug use prevention: the future of drug use prevention world-wide
}

\author{
Giovanna Campello ${ }^{1}$, Zili Sloboda ${ }^{2}$, Hanna Heikkil ${ }^{1}$, Angelina Brotherhood ${ }^{3}$.
}

${ }^{1}$ Prevention, Treatment and Rehabilitation Section, United Nations Office on Drugs and Crime, Vienna, Austria; ${ }^{2}$ Applied Prevention Science, Inc. Ontario, Ohio, United States of America: ${ }^{3}$ Centre for Public Health, Liverpool John Moores University, Liverpool, United Kingdom.

Correspondence: email: giovanna.campello@unodc.org

\begin{abstract}
Over the past 40 years much progress has been made in understanding the aetiology, onset and progression of drug using behaviours, and the effective prevention and treatment of drug use and drug use disorders. Many attempts have been made to summarise this knowledge base and disseminate it so that it is implemented in communities and for people who are in need. These attempts have not been totally effective. This paper reports on initial developmental work by the United Nations Office on Drugs and Crime aimed toward the dissemination and adoption of evidence-based prevention interventions and policies for drug use, the International Standards on Drug Use Prevention. While the Standards document represents progress in the application of rigorous criteria to drug use prevention programming, there remains much more that needs to be done. Not only is there a need to diffuse evidence-based prevention practices internationally but also to sustain the foundational research to allow for continuous improvements over time and to institutionalise the field of prevention science at the practice level. Recommendations for such efforts are discussed.
\end{abstract}

Keywords: Prevention, Evidenced-Based, Family, School, Media, Workplace

\section{Introduction}

The International Standards on Drug Use Prevention document (Standards) ${ }^{1}$ was the brainchild of a group of prevention experts from a number of international agencies including, the Canadian Centre on Substance Abuse, United Nations Office on Drugs and Crime (UNODC), the Inter-American Drug Abuse Control Commission of the Organization of American States, and the European Monitoring Centre on Drugs and Drug Addiction. The group wanted to summarise not only what evidence existed to support the premise that the field now had the knowledge to effectively prevent drug use but also to lay out the key principles and elements that formed the foundation for effective interventions and policies. Although written primarily to inform policy makers, the Standards are a useful tool for all drug use professionals and serves as an excellent basis 
for training drug use prevention researchers and practitioners. The staff of the UNODC with funding from the Governments of Norway, as well as Sweden and Finland and Italy, set out to develop the Standards targeting national policy makers and to pilot test a training seminar that would serve to disseminate them in 2012 and 2013.

\section{Vulnerability, socialisation and prevention}

The 1992 work of Hawkins and his colleagues had moved the field of drug use prevention toward a public health framework addressing those risk factors that had been found to be associated with the onset of drug use. ${ }^{2}$ the enumeration of these risk factors reflected indicators of problems of underlying mechanisms or processes making individuals, mostly children and adolescents, more vulnerable to initiating the use of drugs and progressing from use to abuse and ultimately to drug use disorders. The findings from more recent research have begun to identify the processes of vulnerability implicating impediments of cognitive, emotional, and social developmental processes. ${ }^{3}$

Additional research has found that an important component for human beings is affiliation to any social group. To make positive attachment to social groups means understanding the social context of the group and being sensitive to their social and physical environments. ${ }^{4,5}$ Success within any social group is a balance between what is best for self and what is best for the group. To achieve this balance means recognising the importance of behavioural inhibition. ${ }^{6,7}$ Therefore, successful attachments require the ability to "read" emotions and behaviour and to have good decision making skills about what behaviours are acceptable under various situations. ${ }^{8,9}$

We acquire these social skills through our interaction with various influential groups within our social settings. This interaction is termed socialisation meaning the internalisation of societal goals, and socially acceptable norms, values, and behaviours that are age- and gender-related. The factors that define the socialisation process and outcomes are informed by societal benchmarks. These benchmarks are culturally appropriate applying to language, cognition, identity of self, self-control, as well as expected role performance and behaviours.

During the developmental period from infancy through late adolescence the maturing child moves from a state of dependency to increasing autonomy acquiring the ability to assume his/her adult role in society. Any delay or impairment during this period, if not addressed early, can lead to problem behaviours in adulthood when they are more difficult to treat. ${ }^{10,11}$ The result of delays in cognitive development impedes socialisation and the achievement of good decision-making skills. The lack of such skills increases the level of risk for engagement in behaviours that may have negative social or health outcomes. 
Every society relies on a wide range of socialising agents that provide guidance including parents, teachers, peer groups, religious groups, economic and political organisations and even the mass media. Each serves a different role and applies different influences across the lifespan. For example, if children have parents or caregivers who fail to nurture, who are exposed to ineffective parenting skills in a chaotic family setting, or if the caregiver is a substance abuser or a person with mental illness, the important attachment needed to bond to family and society is greatly compromised. Even with positive parents or caregivers, if young children have any physical or emotional problem such as a difficult temperament, they present challenges to poorly prepared parents. These conditions have the potential to impede significant developmental competencies making a child vulnerable and at risk for negative behaviours later on.

\section{Reconceptualisation of drug use prevention}

As stated above, prevention is concerned primarily with those behaviours that have a detrimental impact on the health, safety, and well-being of individuals, groups, and populations. It is also suggested that drug use and other forms of negative behaviours such as juvenile delinquency, and academic failure are the results of interrupted or poor socialisation. Such a framework suggests that prevention interventions and policies play an important role in the socialisation process in any society. This framework is important, not only as it defines prevention interventions and policies as socialisation agents, but it also emphasises the need for prevention interventions and policies to address socialisation across the lifespan, from the prenatal period through adulthood. ${ }^{12}$

Prevention interventions and policies inform the socialisation process either by training socialisation agents, such as parents and teachers, in 'evidence-based' parenting and teaching techniques shaped to the needs of children and their vulnerabilities. Or, prevention interventions and policies can serve as socialisation agents themselves by directly targeting groups through behavioural interventions or informing social policies.

The combination of this reconceptualisation and our understanding that vulnerability represents a range, not just a "yes"-"no" condition, implies that prevention interventions and policies also are designed to meet the specific needs of individuals and groups. Currently, prevention interventions are developed and tested to address specific populations-namely, universal is 'regardless of risk level' (i.e. risk level unknown, so could include also high-risk children); selective - groups identified through risk factors, i.e. bearing characteristics associated with substance use (e.g. poverty); indicated - individuals who already use but do not yet meet diagnostic criteria for dependence. ${ }^{13}$ As prevention research advances our understanding of the nexus between vulnerability 
and environmental influences, the matching of prevention interventions and policies should become more precise, thus expanding our prevention intervention tools.

\section{The process of development of the international standards}

Advances in prevention evaluations, the re-conceptualisation of prevention interventions and policies as socialisation agents, and the developmental framework shaped the process and format for the development of the Standards. The framework laid out was a multi-phased effort. First, criteria for identification of evidence-based interventions and policies were developed. Next, these criteria were applied to the research findings from both the published and unpublished literature. And the third phase identified interventions and policies that were efficacious in preventing tobacco, alcohol and other drug use, as well as consistent components or principles that were found to be associated with positive, no or negative outcomes.

The UNODC created a Group of Experts (Group), consisting of 85 researchers, policy makers, practitioners, non-governmental agencies, and international organisations who were identified by both UNODC staff through their prevention research and activities and through nominations by Member States. In meetings in 2012, the Group provided general guidance particularly to further refinement of the criteria for evidence-based interventions and to exclusion and inclusion criteria, reviewed a first draft of the document, and advised UNODC regarding the methodology that was to be used to systematically assess the research evidence and in many cases provided materials for review and assessment. Details regarding this process can be reviewed in documents at the UNODC website (www.unodc.org/prevention).

The sources of research reports included those provided by the Group, a systematic review of reviews conducted by the Centre for Public Health at Liverpool John Moores University ${ }^{14}$, and a manual search of Cochrane and Campbell databases. Five hundred and eighty-four studies were submitted for review. A hierarchical review process at two levels including, (1) only substance use and prevention studies and, (2) those with substance use outcomes or studies of the period prior to the age of onset reporting on identified mediating factors that are associated with later substance use, produced 256 eligible studies. These 256 studies were divided into those that were systematic reviews or meta-analyses (137), those that were randomised control trials (60), and those that were primary studies using other designs. Different criteria were applied to each of these groups of studies (for details see the Appendix II of the International Standards document at the UNODC website). Through further review, it was determined that 70 of the 137 systematic reviews, 10 of the 
randomised control trials, and one of the other primary studies were considered of "acceptable" or "good" quality. This assessment only pertains to the conduct and reporting of the studies and does not represent the actual impact of the intervention or policy which may have been positive, negative, and/or mixed or shown inconsistent results.

\section{Figure 1. Summary of the standard review process}

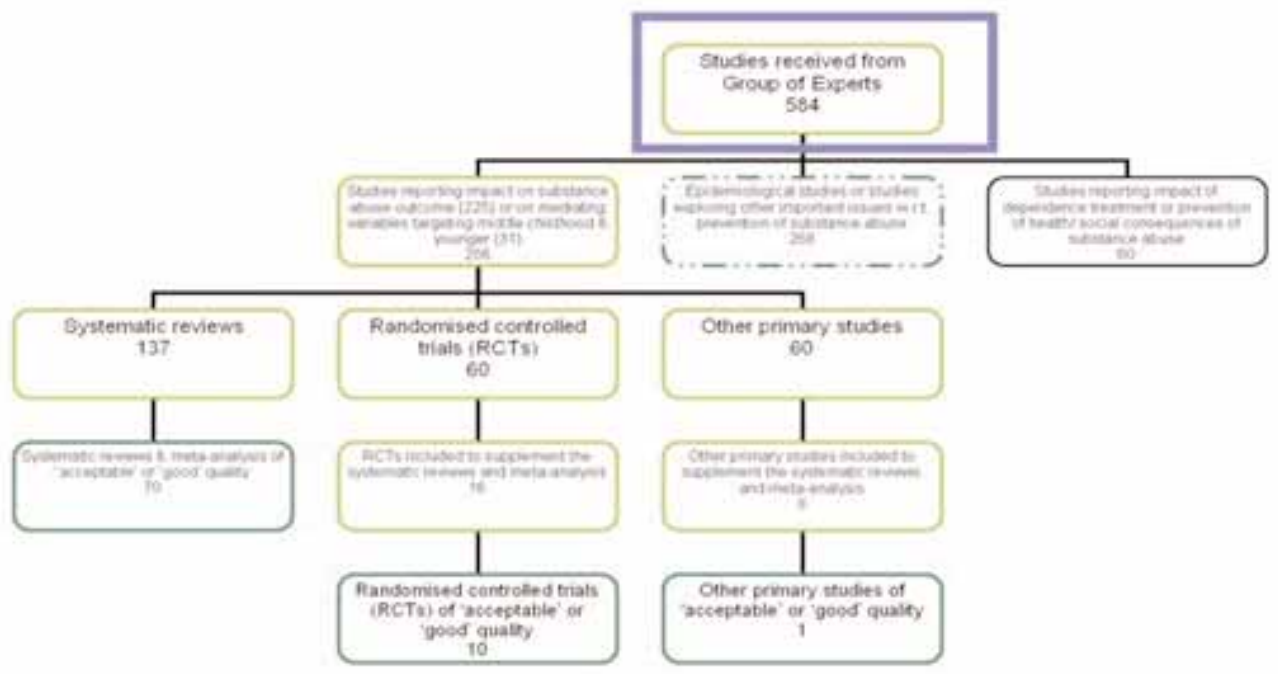

The next step was to summarise the impact of the different interventions and policies on the basis of the studies that were considered to be "acceptable" or "good". Data extraction tables (also available online) were prepared providing the results described in each of these studies by intervention/ policy and this was summarised in the main text of the Standards. Quality

assessment and data extraction were conducted by two independent reviewers, and any disagreements were resolved by consensus or by referral to a third reviewer. Table 1 summarises the findings presenting interventions and policies by targeted age group and by setting/ socialisation agent. Each intervention/ policy is characterised by the vulnerability status of the target group (universal, selective, indicated), as well as an indication of efficacy (* limited, ** adequate, $* * *$ good, $* * * *$ very good, $* * * * *$ excellent).

\section{Prevention interventions and policies}

The International Standards on Drug Use Prevention presents three aspects for each evidence-based prevention strategy: a brief description of the strategy, a summary of the available evidence, and those characteristics that are linked to 
outcomes. In some cases, the strategy may be applicable to two age groups such as for middle childhood and early adolescence, or adolescence and adulthood, with this overlap indicated in the text. There is no sufficient space in this article to cover the details of each strategy but a brief overview is presented for each age group along with tables of the strategies content, structure, and delivery characteristics. Where available the characteristics of strategies that were found to have no or negative outcomes are included.

Table 1. Summary indicating efficacy

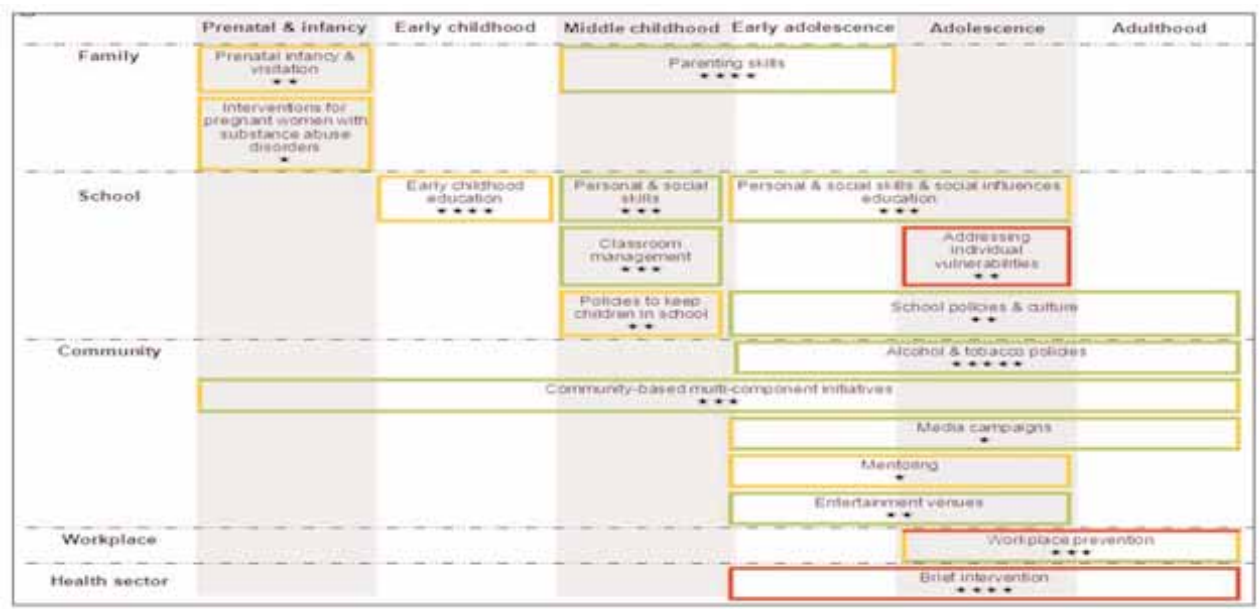

\section{Prenatal and infancy}

This is a crucial time for children when their earliest human interactions occur within the family. The family should be a place of nurturing, love, and safety. It is also the place that influences how infants, children and adolescents perceive and interact with the world around them whether with family members, neighbors, school or the community. How parents and caretakers perform these roles is important for normal development.

Interventions that had positive effects on this period of development were primarily selective and include: interventions that target pregnant women with substance abuse disorders (evidence of effectiveness is limited), and, prenatal and infancy visitation (evidence of effectiveness is adequate). 
Interventions for pregnant women with substance abuse disorders characteristics

\begin{tabular}{|l|ll|}
\hline Content & $\bullet$ & $\begin{array}{l}\text { Pharmacological and/or psychosocial therapy } \\
\text { that is voluntary, based on scientific evidence } \\
\text { and tailored to the patient }\end{array}$ \\
& $\bullet$ & $\begin{array}{l}\text { Treatment of co-morbid physical and mental } \\
\text { health disorders } \\
\text { Provide attachment-based parenting interven } \\
\text { tions }\end{array}$ \\
\hline Structure & $\bullet$ & Integrated treatment services \\
\hline Delivery & $\bullet$ & Trained health workers \\
\hline
\end{tabular}

Visitation programmes characteristics linked to positive outcomes

\begin{tabular}{|l|cl|}
\hline Content & $\bullet$ & $\begin{array}{l}\text { Basic parenting skills } \\
\text { Support mothers to address a range of issues } \\
\text { including health, housing, employment, etc. }\end{array}$ \\
\hline Structure & $\bullet$ & $\begin{array}{l}\text { Regular visits up to two years of the age of the } \\
\text { baby, at first every two weeks and then every } \\
\text { month }\end{array}$ \\
\hline Delivery & $\bullet$ & Trained health workers \\
\hline
\end{tabular}

\section{Early childhood}

This is a period when children begin to explore the outside world. An intervention that was found to be effective with children from deprived communities (a selective intervention) was early childhood education. This strategy is designed to support the cognitive and social development of pre-school aged children (generally aged two to five years). 


\section{Early childhood education characteristics linked to positive outcomes}

\begin{tabular}{|l|ll|}
\hline Content & $\bullet$ & Cognitive skills \\
& $\bullet$ & Social skills \\
& $\bullet$ & Language skills \\
& $\bullet$ & Provide socio-economic support to families \\
\hline Structure & $\bullet$ & Delivered daily \\
\hline Delivery & $\bullet$ & Trained teachers \\
\hline
\end{tabular}

\section{Middle childhood}

Children in this age group are beginning to spend more time away from their families, most often in schools and with their same-aged peers. Therefore they are exposed to the influences of other adults and demands on their social and cognitive competencies are increased. Among the developmental goals of middle childhood are continuing to enhance their language and numeracy skills and decision making and problem solving skills and to achieve impulse control. It is during this period that potential problems related to individual vulnerabilities are observed by teachers and other adults with whom children interact during this period. Opportunities to address these issues with evidence-based prevention interventions and policies serve to alter future trajectories for many vulnerable children.

For this period, effective prevention interventions and policies include parenting skills programs, personal and social skills development, classroom management, policies that keep children in school, and addressing individual vulnerabilities.

The family and specifically parents remain primary socialisation agents during this time. Parenting skills programs that were rated as "good" support parents to perform effectively. 


\section{Parenting skills characteristics}

\begin{tabular}{|c|c|c|}
\hline & Linked to Positive Outcomes & $\begin{array}{l}\text { Linked to No or Negative } \\
\text { Outcomes }\end{array}$ \\
\hline Content & $\begin{array}{l}\text { - Enhance family bonding } \\
\text { - } \text { Provide skills for } \\
\text { - Warm child-rearing } \\
\text { - Setting rules for acceptable } \\
\text { behaviour } \\
\text { - Monitoring free time and } \\
\text { friendship patterns } \\
\text { - Positive and developmentally } \\
\text { appropriate discipline } \\
\text { - Involvement in children’s } \\
\text { learning and education } \\
\text { - Becoming role models }\end{array}$ & $\begin{array}{l}\text { - Provide information to } \\
\text { parents about drugs } \\
\text { - Undermine parents' } \\
\text { authority }\end{array}$ \\
\hline Structure & $\begin{array}{l}\text { - Multiple group sessions } \\
\text { - Interactive }\end{array}$ & $\begin{array}{l}\text { - Focus exclusively on the } \\
\text { child } \\
\text { - Lecture as only means of } \\
\text { delivery }\end{array}$ \\
\hline Delivery & $\begin{array}{l}\text { - } \text { Trained instructors } \\
\text { - } \text { Organised to facilitate } \\
\text { participation }\end{array}$ & - Poorly trained instructors \\
\hline
\end{tabular}


Another type of evidence-based universal prevention intervention that was rated as "good" is the personal and social skills-focused education programme. These are generally delivered in schools by trained teachers and give children opportunities through interactive activities to learn and practice such skills as coping with challenges and decision making.

\section{Personal and social skills-focused education characteristics}

\begin{tabular}{|c|c|c|}
\hline & Linked to Positive Outcomes & $\begin{array}{l}\text { Linked to No or Negative } \\
\text { Outcomes }\end{array}$ \\
\hline Content & $\begin{array}{l}\text { - Coping skills } \\
\text { - Personal skills } \\
\text { - Social skills }\end{array}$ & $\begin{array}{l}\text { - Providing information on } \\
\text { specific substances } \\
\text { - Focus only on self-esteem } \\
\text { - Focus only on emotional } \\
\text { education } \\
\text { - Fear arousal }\end{array}$ \\
\hline Structure & $\begin{array}{l}\text { - Structured series of sessions } \\
\text { - Possibly, booster sessions, } \\
\text { over multiple years }\end{array}$ & \\
\hline Delivery & $\begin{array}{l}\text { - Trained teachers } \\
\text { - Interactive methods of } \\
\text { delivery }\end{array}$ & $\begin{array}{l}\text { - Using untrained teachers } \\
\text { - } \quad \text { Primarily using non- } \\
\text { interactive methods }\end{array}$ \\
\hline
\end{tabular}

Classroom environmental improvement programs were also found to be effective (rated as "good") for this age group. These universal interventions are designed to strengthen the classroom management skills of teachers to support students to enhance their performance in their role as students while at the same time reducing aggressive and disruptive behaviour. 


\section{Classroom environment improvement programmes characteristics linked to positive outcomes}

\begin{tabular}{|l|cl|}
\hline Content & $\bullet$ & $\begin{array}{l}\text { Strategies designed for teachers to respond to } \\
\text { inappropriate behaviour and to } \\
\text { acknowledge appropriate behaviour } \\
\end{array}$ \\
\hline Structure & $\bullet$ & Provide feedback on expectations \\
& - & $\begin{array}{l}\text { Actively engages students } \\
\text { Delivered in first school years }\end{array}$ \\
\hline Delivery & $\bullet$ & Trained teachers \\
\hline
\end{tabular}

Finally, policies designed to keep children in school have been found to have adequate evidence to support effectiveness. These policies have been found to increase school attendance and attachment to schools and therefore the achievement of age-appropriate language and numeracy skills. These policies were tested primarily in low- and middle-income countries.

\section{Adolescence}

Adolescents generally are exposed to more groups outside of the home as well as to new ideas and behaviours. This is a period when young people begin to 'try on' adult roles while still in protective environments. It is also a period when the human brain is still plastic and malleable providing opportunities for evidence-based prevention interventions to reinforce or alter earlier experiences. Both parenting skills and personal and social skills-types of prevention interventions have been found to be effective for this age group. 
Personal and social skills-education added characteristics

\begin{tabular}{|c|c|c|}
\hline & Linked to Positive Outcomes & $\begin{array}{l}\text { Linked to No or Negative } \\
\text { Outcomes }\end{array}$ \\
\hline Content & $\begin{array}{l}\text { - Addresses perceptions } \\
\text { of risk or harm associated } \\
\text { with substance use } \\
\text { - Emphasises immediate } \\
\text { age-appropriate consequences } \\
\text { of substance use }\end{array}$ & $\begin{array}{l}\text { - Information only } \\
\text { - Focus only on self-esteem } \\
\text { - Focus only on emotional } \\
\text { education } \\
\text { - Address only ethical/moral } \\
\text { decision making or values }\end{array}$ \\
\hline Structure & $\begin{array}{l}\text { - Structured series of interactive } \\
\text { sessions } \\
\text { - Booster sessions }\end{array}$ & $\begin{array}{l}\text { - Unstructured dialogue } \\
\text { sessions } \\
\text { - Primarily using non- } \\
\text { interactive methods }\end{array}$ \\
\hline Delivery & - Trained teachers & $\begin{array}{l}\text { - Using untrained teachers } \\
\text { - Use ex-drug users as } \\
\text { testimonials }\end{array}$ \\
\hline
\end{tabular}

As this is generally the period when substance use is initiated, school policies and school culture serve an important role in reinforcing non-substance use. But to be effective, these policies need to have specific characteristics. 
School policies and culture characteristics

\begin{tabular}{|c|c|c|}
\hline & Linked to Positive Outcomes & $\begin{array}{l}\text { Linked to No or Negative } \\
\text { Outcomes }\end{array}$ \\
\hline Content & $\begin{array}{l}\text { - Policies clearly specific what } \\
\text { substances are targeted and } \\
\text { what locations and/or occasions } \\
\text { they apply to } \\
\text { - Reducing or eliminating } \\
\text { availability of and access } \\
\text { to tobacco, alcohol, } \\
\text { or other drugs } \\
\text { - Address infractions o } \\
\text { substance use policies } \\
\text { with positive sanctions, } \\
\text { providing referral to counseling } \\
\text { or other support services } \\
\text { NOT punishment } \\
\text { - Support normal school } \\
\text { functioning NOT disruption } \\
\text { - Support positive school } \\
\text { ethos and commitment to } \\
\text { school and student participation }\end{array}$ & $\begin{array}{l}\text { - Punish infractions of } \\
\text { substance use policies } \\
\text { (e.g. suspension, } \\
\text { expulsion) } \\
\text { - Random drug testing }\end{array}$ \\
\hline Structure & $\begin{array}{l}\text { - Participation of all stakeholders } \\
\text { (students, parents, and school staff) } \\
\text { in the development of substance } \\
\text { use-related policies }\end{array}$ & \\
\hline Delivery & $\begin{array}{l}\text { - Implemented with other prevention } \\
\text { interventions such as skills-based } \\
\text { education or parenting skills }\end{array}$ & \\
\hline
\end{tabular}


As indicated earlier it is during this period when some personality traits such as sensation-seeking, impulsivity, anxiety sensitivity or depression are identified. There is adequate evidence that prevention interventions that address these individual psychological vulnerabilities are effective.

\section{Individual psychological vulnerabilities intervention characteristics linked to Positive outcome}

\begin{tabular}{|l|l|}
\hline Content & $\begin{array}{l}\text { Provide skills on how to positively cope } \\
\text { with emotions }\end{array}$ \\
\hline Structure & $\begin{array}{l}\text { - Sessions tend to be short (about one hour), } \\
\text { between } 2 \text { and } 5 \text { in number }\end{array}$ \\
\hline Delivery & $\begin{array}{l}\text { - Screening done using validated instruments } \\
\text { - Trained professionals }\end{array}$ \\
\hline
\end{tabular}

Having positive role models has been shown to help adolescents take on more responsible roles and to make positive life decisions, but positive evidence for mentoring interventions is sparse.

\section{Mentoring characteristic}

\begin{tabular}{|l|l|l|}
\hline & Linked to Positive Outcomes & Linked to negative outcomes \\
\hline Structure & $\begin{array}{l}\text { - Very structured program of } \\
\text { activities }\end{array}$ & \\
\hline Delivery & $\bullet$ Trained mentors & $\begin{array}{l}\text { Mentors that are not trained } \\
\text { and/or supported. }\end{array}$ \\
\hline
\end{tabular}

\section{Adolescence and adulthood}

Older adolescents expand their world-experiences beyond family and school into the workplace, the health sector, entertainment venues, and the community. In addition to the interventions discussed under adolescence above, evidencebased interventions and policies were found in these new venues: workplace prevention programmes, tobacco and alcohol policies, media campaigns, and community-based multi-component initiatives.

The workplace, like the school, is a place where social as well as work skills shape individuals' lives. The workplace is a source of economic and social support but also a place of stress, presenting opportunities for substance use. 
Workplace prevention programme characteristics linked to positive outcomes

\begin{tabular}{|c|c|}
\hline Content & $\begin{array}{ll}\text { - } & \text { Multiple components that include both policies and } \\
\text { interventions } \\
\text { - } & \text { Provide brief intervention (including web-based) } \\
\text { - } & \text { Include a clear communication component } \\
\text { - } & \text { Use alcohol and drug testing ONLY as part of this } \\
\text { - } & \text { Stremprehensive program } \\
\text { - } & \text { Strenagement courses }\end{array}$ \\
\hline Structure & $\begin{array}{l}\text { Guarantee confidentiality } \\
\text { - } \quad \begin{array}{l}\text { Developed with the involvement of all stakeholders } \\
\text { (employees, management, employers, and unions }\end{array} \\
\text { when applicable), } \\
\text { - } \quad \begin{array}{l}\text { Embedding the substance use prevention interven- } \\
\text { tion in other health or wellness-related programs }\end{array}\end{array}$ \\
\hline Delivery & $\begin{array}{l}\text { - Non-punitive approach that guarantees confidentiali- } \\
\text { ty and access to counselling and treatment are } \\
\text { important components } \\
\text { - Trains managers, employees and workplace health } \\
\text { staff about their role in prevention interventions and } \\
\text { policies }\end{array}$ \\
\hline
\end{tabular}

The evidence for brief interventions designed for 'at-risk' adolescents and adults has been given a rating of "very good". They are delivered in a variety of settings including health facilities to persons who use substances and may be at risk for progression to abuse and who would not necessarily need or seek treatment. 


\section{Brief interventions characteristics linked to positive outcomes}

\begin{tabular}{|l|l|}
\hline Content & $\begin{array}{l}\text { - Screening } \\
\text { - Brief intervention or referral to treatment } \\
\text { - Addressing the relationship of substance use and goals } \\
\text { of the individual }\end{array}$ \\
\hline Structure & $\begin{array}{l}\text { • One-to-one counselling } \\
\text { - Structured sessions }\end{array}$ \\
\hline Delivery & - Trained health and social service workers \\
\hline
\end{tabular}

Community prevention interventions and policies that were included in the Standards address broader populations such as whole communities, states/provinces, and nations. These were tobacco and alcohol policies, interventions in entertainment venues, media campaigns, and, community-based multi-component initiatives.

Tobacco and alcohol policies are relevant to an overall substance use strategy as most youth who use drugs, often also use these substances. The available evidence for these policies was considered "adequate".

\section{Tobacco and alcohol policies characteristics linked to positive outcomes}

\begin{tabular}{|l|l|}
\hline Content & $\begin{array}{l}\text { • Reduce access of tobacco and alcohol to underage } \\
\text { children and adolescents }\end{array}$ \\
& - Reduce availability of tobacco and alcohol products \\
\hline Structure & • Increase price through taxation \\
& - Minimum age for sale \\
& - Comprehensive prevention strategies \\
\hline Delivery & - Active and consistent law enforcement \\
& - Education of retailers \\
& - Banning advertisement of tobacco \\
& targeting youth \\
\hline
\end{tabular}


Along with these policies, prevention interventions delivered in entertainment venues such as bars, clubs, restaurants, and outdoor settings where large events occur have "adequate" evidence of effectiveness. These interventions along with the tobacco and alcohol policies aim to reinforce negative attitudes and norms regarding the use of these substances among young people and the abuse of them by adults.

\section{Entertainment venues interventions characteristics linked to positive outcomes}

\begin{tabular}{|l|l|}
\hline Content & $\begin{array}{l}\text { - Having the skills to identify underage patrons for } \\
\text { alcohol service and intoxicated patrons } \\
\text { - Management of intoxicated patrons }\end{array}$ \\
\hline Structure & $\begin{array}{l}\text { - Includes active participation of representatives of } \\
\text { law enforcement, health and social service sector } \\
\text { - Counseling and treatment for staff and } \\
\text { management who need it }\end{array}$ \\
Delivery & $\begin{array}{l}\text { - Raise awareness and acceptance of the program } \\
\text { Trained serving staff and managers }\end{array}$ \\
\hline
\end{tabular}

The evidence-base for the positive effects of media campaigns was "limited". Media campaigns are often the first and sometimes the only prevention intervention delivered within a geographic area. Media campaigns are thought to have visibility and have the potential to reach large numbers of people. However, unless they are well-designed and implemented as part of a multi-component programme, they have minimal if any impact. 
Media campaign characteristics

\begin{tabular}{|c|c|c|}
\hline & Linked to Positive Outcomes & $\begin{array}{l}\text { Linked to No or Negative } \\
\text { Outcomes }\end{array}$ \\
\hline Content & $\begin{array}{l}\text { - Have a solid theoretical basis } \\
\text { - Change cultural norms about } \\
\text { substance use } \\
\text { - Educate about the consequences } \\
\text { of substance use } \\
\text { - Suggest strategies to resist } \\
\text { substance use } \\
\text { - Target parents as this appears to } \\
\text { have an independent effect also on } \\
\text { children }\end{array}$ & $\begin{array}{l}\text { - Exaggerated, unrealistic } \\
\text { threats }\end{array}$ \\
\hline Structure & $\begin{array}{l}\text { - Deliver messages based on strong } \\
\text { formative research } \\
\text { - Connect with other existing drug } \\
\text { use prevention programs } \\
\text { - Achieve adequate exposure } \\
\text { - On-going systematic evaluations to } \\
\text { adjust messaging }\end{array}$ & $\begin{array}{l}\text { - Poorly thought out } \\
\text { and poorly designed } \\
\text { - Poorly resourced }\end{array}$ \\
\hline Delivery & $\begin{array}{l}\text { - Precisely define the target } \\
\text { population }\end{array}$ & \\
\hline
\end{tabular}


Although not directly an intervention or policy, community-based multicomponent initiatives have been found to have "good" evidence of effectiveness. In general these initiatives mobilise a cross-section of a community to address substance use using multiple interventions and policies through the formation of task forces or partnerships.

\section{Community-based multi-component initiatives characteristics}

- Support the enforcement of tobacco and alcohol policies

- Include a range of settings such as families and schools

- Provide training and resources to the community

- Involve universities to support both implementation with monitoring and evaluation, and

- Sustain prevention initiatives for more than one year

\section{Conclusions}

The Standards document is a landmark effort for the field of prevention science. It is the first effort of its kind to apply rigorous criteria to the review of the literature on drug use prevention interventions and policies. Furthermore, it used a framework that allows the reader to understand the extent to which the interventions and policies serve to enable the targeted populations to achieve their developmentally appropriate benchmarks. Finally, although it was designed to inform policy makers, it is a resource for all drug use prevention professionals. There are two important and related issues raised in the standards: areas for further research and the development of infrastructures to support the delivery of evidence-based prevention interventions and policies.

\section{Research}

- In addition to the need for more research addressing all of the interventions and policies that have some evidence of effectiveness, more systematic reviews are needed summarising the research to date.

- In addition, there is a need to understand what mechanisms underlie the effectiveness of these interventions and policies and to identify the contributions that individual and combined intervention components make to positive outcomes.

- Most of the interventions and policies described in the Standards have been evaluated in western or developed countries. The extent to which these are relevant in other cultures and settings needs to be determined.

- Also more quality research addressing the prevention import of sports and leisure time activities is needed. 
- Other areas that warrant attention include the prevention of the nonmedical use of prescription drugs and new psychoactive substances not currently under control of the conventions and interventions.

- Finally, evidence-based interventions and policies are needed that target children and youth who are at high risk for substance use such as out-of-school youth, street children, current and ex-child soldiers, children and youth of displaced or post-conflict populations, children in foster care, in orphanages and in the juvenile justice system.

\section{Infrastructure development}

- Finally, with the advances made in identifying evidence-based prevention interventions and policies, there remains the need for institutionalising a comprehensive drug use prevention system

- Such a system requires

- a supportive policy and legal framework

- a strong research programme

- the coordination of multiple sectors at all levels (national, sub-national, and local)

- $\quad$ training at all levels from policy makers to practitioners to understand the important role prevention plays in any society and the significance of implementing evidence-based interventions and policies with quality controls in place; and

- a long term commitment to provide adequate resources to sustain an effective prevention system

\section{References}

1. United Nations Office on Drugs and Crime. International Standards on Drug Use Prevention. 2013 Vienna: UNODC.

2. Hawkins JD, Catalano RF, Miller JY. Risk and protective factors for alcohol and other drug problems in adolescence and early adulthood: Implications for substance abuse prevention. Psycho Bull. 1992; 112:64-105.

Doi: http://dx.doi.org/10.1037/0033-2909.112.1.64

PMid:1529040 
3. Fishbein DH, Ridenour TA. Advancing transdisciplinary translation for prevention of high-risk behaviours: Introduction to the Special Issue. Prev Sci. 2013;14:201-205.

Doi: http://dx.doi.org/10.1007/s11121-013-0394-6

PMid:23579566

4. Blakemore SJ. The social brain in adolescence. Nat Rev Neurosci. 2008; 9:267-277.

Doi: http://dx.doi.org/10.1038/nrn2353

PMid:18354399

5. Frith CD. The social brain? Philos T Roy Soc. 2007; 363:671-678.

Doi: http://dx.doi.org/10.1098/rstb.2006.2003

PMid:17255010 PMCid:PMC1919402

6. Heatherton TF, Wheatley T. Social neuroscience. In: Baumeister, RF \& Finkel, E. (eds.) Advanced Social Psychology. 2010. New York: Oxford University Press, 2010;575-612.

7. Zucker RA., Heitzeg MM., Nigg JT. Parsing the undercontrol/disinhibition pathway to substance use disorders: A multilevel developmental problem. Child Dev Per. 201;5:248-55.

Doi: http://dx.doi.org/10.1111/j.1750-8606.2011.00172.x

PMid:22116786 PMCid:PMC3221325

8. Bechara A. Decision making, impulse control, and loss of willpower to resist drugs: A neurocognitive perspective. Nat Neurosci. 2005; 8:1458-63.

Doi: http://dx.doi.org/10.1038/nn1584

PMid:16251988 
9. Van Leijenhorst L, Gunther Moor B, Op de Macks ZA, Rombouts SA, Westenberg P M, Crone, EA. Adolescent risky decision-making: Neurocognitive development of reward and control regions. Neuroimage. 2010; 51:345-55.

Doi: http://dx.doi.org/10.1016/j.neuroimage.2010.02.038

PMid:20188198

10. Moffitt, TE. Adolescence-limited and life-course-persistent antisocial behaviour: A developmental taxonomy. Psychol Rev. 1993;100:674701.

Doi: http://dx.doi.org/10.1037/0033-295X.100.4.674

PMid:8255953

11. Patterson, GR, Forgatch, MS, Voerger, KL, Stoolmiller, M. Variables that initiate and maintain an early-onset trajectory of offending. Dev Psychopathol. 1998;10:531-47.

Doi: http://dx.doi.org/10.1017/S0954579498001734

PMid:9741681

12. Sloboda, Z. Vulnerability and risks: Implications for understanding etiology and drug use prevention. In: Scheier LM. (ed.). Handbook of Drug Prevention. Washington, D.C.: American Psychological Association. Forthcoming.

13. European Monitoring Centre on Drugs and Drug Addiction, http://www.emcdda.europa.eu/publications/thematic-papers/indicatedprevention

14. Brotherhood A, Atkins AM, Bates G, Sumnall HR. Adolescents as customers of addiction. ALICE RAP Deliverable 16.1. Work Package 16. 2013. Liverpool: Liverpool Centre for Public Health. 